\title{
PRODUÇÃO DE PECTINASES EM MEIO OTIMIZADO DE FARINHA DE MARACUJÁ E AVALIAÇÃo DA ATIVIDADE PECTINOLÍTICA
}

\author{
Natacha Alzenda Anet Afonso' ${ }^{1}$;atheus Mikio Takeyama ${ }^{2}$; Ana Elizabeth C. Fai B. de \\ Gusmão $^{3,4}$; Maria Gabriela Bello Koblitz ${ }^{1,3}$ (natacha.alzenda@gmail.com)
}

\author{
1Departamento de Ciência de Alimentos; Escola de Nutrição; Universidade Federal do Estado do Rio de \\ Janeiro (UNIRIO). \\ 2 Faculdade de Farmácia; Centro de Ciências da Saúde; Universidade Federal do Rio de Janeiro (UFRJ). \\ 3Programa de Pós-Graduação em Alimentos e Nutrição (PPGAN) - Universidade Federal do Estado do Rio de \\ Janeiro (UNIRIO), Brasil \\ 4 Departamento de Nutrição Básica e Experimental, Instituto de Nutrição, Universidade do Estado do Rio de \\ Janeiro (UERJ).
}

O Brasil continua sendo o maior produtor e consumidor mundial de maracujá, produzindo cerca de 800 mil toneladas deste fruto por ano. O rendimento de resíduo de maracujá é de 65 a $70 \%$ do fruto, justificando estudos que apresentem alternativas para seu aproveitamento e a produção de coprodutos de valor agregado, representando ganhos ambientais e econômicos. A casca do maracujá é rica em proteínas, pectina e outras fibras. Gerada em grandes quantidades, apresenta potencial para diversas aplicações, como alimentação animal e até mesmo como suplemento dietético e também pode ser empregada no setor biotecnológico, para a produção de biocombustíveis e como substrato para a produção de enzimas como celulases, pectinases e proteases. Esse trabalho teve por objetivo a produção de enzimas pectinolíticas em meio previamente otimizado de farinha de maracujá por linhagem selecionada de Saccharomyces cerevisiae 38, isolada de cachaçaria, e a caracterização parcial das pectinases produzidas. Para isso, a levedura foi cultivada em meio contendo $50 \%$ de farinha de maracujá e $50 \%$ de tampão $(\mathrm{pH}=5,0)$, por $24 \mathrm{~h}$, a $30^{\circ} \mathrm{C}$. Em seguida o meio foi adicionado de $1 \mathrm{~mL}$ de água para cada grama de meio e centrifugado para obtenção do extrato bruto enzimático. Foram avaliadas a atividade pectinolítica total - sobre pectina cítrica, determinando-se o teor de ácidos galacturônicos liberados pelo método de DNS - e a atividade de pectato liase - sobre ácido péctico, determinando-se a liberação de uronídeos insaturados por absorção a $235 \mathrm{~nm}$. Como resultado observou-se atividade pectinolítica total de 28,28 U/min. Não foi verificada atividade de pectato liase no extrato bruto enzimático. Conclui-se, portanto, que foi possível verificar a habilidade do extrato bruto secretado por linhagem de $S$. cerevisiae 38 de hidrolisar pectina, porém aparentemente essa habilidade não está ligada à atividade de pectato liase. Este trabalho permanece em andamento para purificação e caracterização das pectinases produzidas pela linhagem de S. cerevisiae estudada.

Palavras-chave: Enzimas pectinolíticas, Levedura, Biotecnologia. 